\title{
Social accountability and the supply of physicians for remote rural Canada
}

\author{
Roger Strasser MBBS MCISC
}

See related CMAJ Open research article, www.cmajopen.ca/content/3/2/E217

A study published in CMAJ Open reports on the practice locations in 2014 of Memorial University of Newfoundland (MUN) medical graduates from 1973 to $2008 .{ }^{1}$ Its findings are notable in the context of recent endeavours to improve the supply of physicians to rural communities. In 2001, the medical schools of Canada committed to social accountability, and in 2010 they renewed that commitment in a report entitled "Future of Medical Education in Canada (FMEC): a Collective Vision for MD Education." 2 The focus on responding to health care needs is particularly pertinent in rural communities, many of which have never had a sufficient supply of physicians to ensure equitable access to care.

Mathews and colleagues ${ }^{1}$ found that most of the MUN medical graduates working as physicians in 2014 were working in Canada, with about one-third remaining in Newfoundland and Labrador (NL), and much smaller percentages working in rural communities, especially in rural NL. Compared with results from an earlier study that looked at MUN medical graduates' work locations in $2004,{ }^{3,4}$ the current findings show a drop in the proportion of alumni working in Canada, rural Canada and rural NL, and an increase in the proportion working in NL overall.

It is difficult to say whether these trends are generalizable beyond NL, because similar studies have not been published for other Canadian medical schools. Many factors have been shown to contribute to increasing the supply of rural physicians. ${ }^{5}$ In addition to having a rural background, having positive rural clinical and educational experiences plays a key role. ${ }^{5}$ Other factors include financial incentives and rewards, personal and professional supports, and regulatory initiatives. ${ }^{5}$ Drawing on this evidence, there is a growing belief that the supply of physicians in rural communities will be assured by linking these factors into a comprehensive rural training pathway. ${ }^{6}$

Several Canadian medical schools, beginning with the University of British Columbia's Northern Medical Program in Prince George ${ }^{7}$ and the
Centre de formation médicale du NouveauBrunswick in Moncton, ${ }^{8}$ have established satellite campuses in rural regional centres, which espouse social accountability by responding to the needs of the community. In 2005, the Northern Ontario School of Medicine (NOSM) opened as a stand-alone medical school in a rural region with a focus on improving the health of people in northern Ontario. ${ }^{9}$

Guided by a social accountability mandate, NOSM developed a full range of education and training activities as part of a comprehensive pathway that begins in high school and extends to continuing medical education. The initiatives in high school motivate young people in northern Ontario to aspire to medicine, and the medical school's admissions process favours applicants from northern Ontario or similar sociocultural backgrounds. Distributed, community-engaged learning - NOSM's distinctive model of medical education and health research - ensures that students and residents are learning to practise in the northern Ontario context. The school's comprehensive package is showing signs of success. Studies designed to track medical students and dietetic interns and to assess the socioeconomic impact of NOSM showed that $91 \%$ of the medical students come from northern Ontario, with the remainder coming from remote rural parts of the rest of Canada. ${ }^{10}$ Canada has seen an increase in medical graduates choosing family medicine. A high proportion $(61 \%)$ of NOSM graduates choose family medicine training. ${ }^{10}$ After resi-

\section{KEY POINTS}

- Many remote areas do not have a sufficient supply of physicians to ensure equitable access to care.

- Medical schools around the world that are interested in training physicians as part of a social accountability mandate are now part of the Training for Health Equity Network (THEnet).

- Medical schools can enhance the supply of physicians to rural communities through recruitment of students from underserved rural settings, active participation of rural communities in curriculum development, clinical education by rural clinicians and the offering of residency training in rural practice. 
dency training, $69 \%$ of alumni choose to practise in northern Ontario and $22 \%$ in remote rural communities. $^{10}$

Medical schools around the world that are interested in training physicians as part of a social accountability mandate are now part of the Training for Health Equity Network (THEnet). Members of THEnet share a core mission to recruit students from and produce health professionals for underserved communities. Although these schools operate in different contexts and use somewhat different strategies, they share a set of nine core principles, including targeting education and research to the health and social needs of the community and recruiting students from communities with the greatest need.

THEnet developed, pilot tested and published an evaluation framework for socially accountable health professional education. ${ }^{11}$ THEnet provided the core content for the Global Consensus for Social Accountability of Medical Schools in 2010. Subsequently, THEnet has been successful in researching, reporting and advocating for socially accountable education.

The achievements of NOSM and other member schools of THEnet show clearly that a multifactorial approach is required for medical schools to contribute successfully to the supply of physicians in rural communities. ${ }^{12}$ The experiences of THEnet medical schools provide the basic strategies for improving the supply of physicians in chronically underserved remote rural communities in Canada and elsewhere.

\section{References}

1. Mathews M, Ryan D, Samarasena A. Work locations in 2014 of medical graduates of Memorial University of Newfoundland: a cross-sectional study. CMAJ Open 2015;3:E217.

2. The future of medical education in Canada (FMEC): a collective vision for MD education. Ottawa: Association of Faculties of Medicine of Canada; 2010. Available: www.afmc.ca/future-of-medical -education-in-canada/medical-doctor-project/pdf/collective_vision .pdf (accessed 2015 May 21).

3. Mathews M, Rourke JTB, Park AD. National and provincial retention of medical graduates of Memorial University. CMAJ 2006;175:357-60.

4. Mathews M, Park AD, Rourke JTB. The contribution of Memorial University's medical school to rural physician supply. Can J Rural Med 2008:13:15-21.

5. Increasing access to health workers in remote and rural areas through improved retention: global policy recommendations. Geneva: World Health Organization; 2010. Available: www.who. $\mathrm{int} / \mathrm{hrh} /$ retention/guidelines/en (accessed 2015 May 21).

6. Cairns consensus statement on rural generalist medicine. 2015 World Summit: Rural Generalist Medicine; 2015 Apr. 8-9; Montréal. Available: www.ruralgeneralismsummit.net/cairns -consensus-statement-on-rural-generalist-medicine (accessed 2015 May 21).

7. Lovato C, Bates J, Hanlon N, et al. Evaluating distributed medical education: What are the community's expectations? Med Educ 2009;43:457-61.

8. Schofield A, Bourgeois D. Socially responsible medical education: innovations and challenges in a minority setting. Med Educ 2010;44:263-71.

9. Tesson G, Hudson GL, Strasser R, et al. The making of the Northern Ontario School of Medicine: a case study in the history of medical education. Montréal: McGill-Queen's University Press; 2009.

10. Strasser R, Hogenbirk JC, Minore B, et al. Transforming health professional education through social accountability: Canada's Northern Ontario School of Medicine. Med Teach 2013:35:490-6.

11. Larkins SL, Preston R, Matte MC,et al. Measuring social accountability in health professional education: development and international pilot testing of an evaluation framework. Med Teach 2013;35:32-45.

12. Strasser R, Neusy AJ. Context counts: training health workers in and for rural areas. Bull World Health Organ 2010;88:777-82.

Affiliation: Northern Ontario School of Medicine (Strasser), Lakehead University, Thunder Bay, Ont., and Laurentian University, Sudbury, Ont.

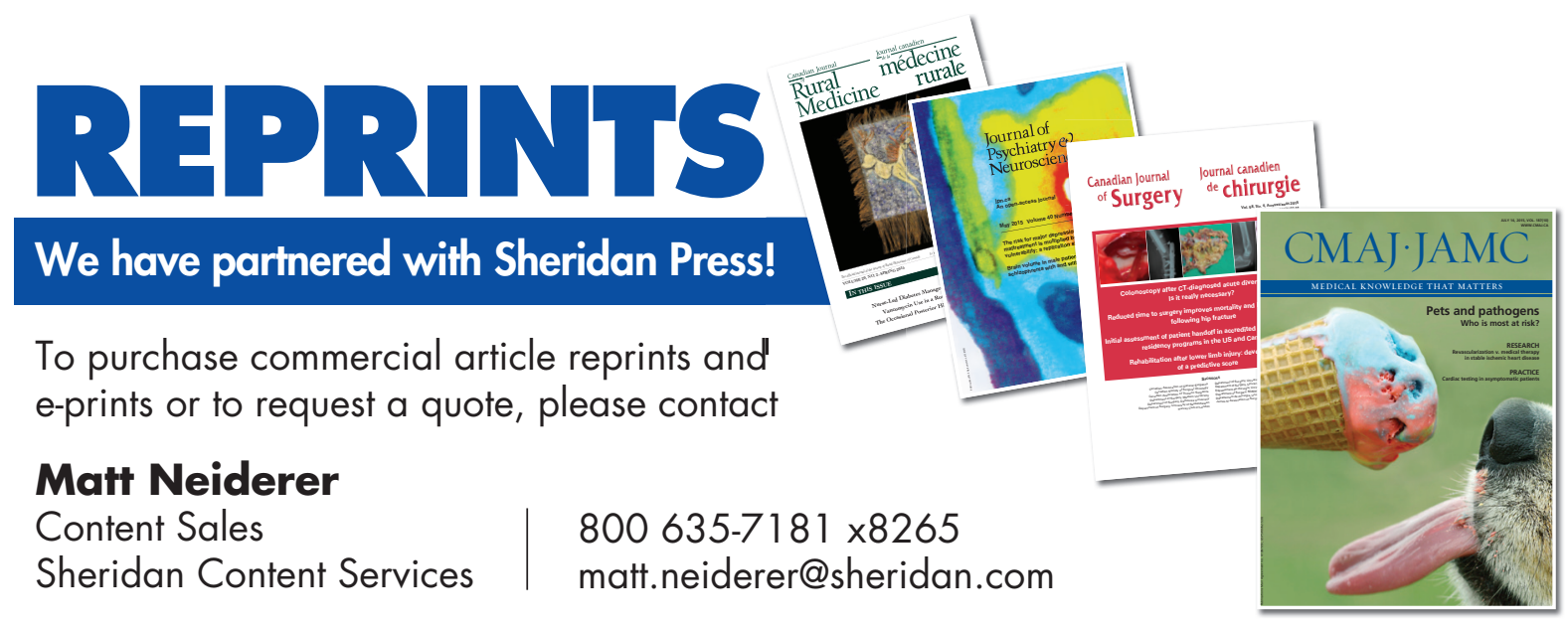

